\title{
GIS-BASED DIGITAL APPLICATIONS ON MAINTENANCE AND PRESERVATION FOR TRADITIONAL CHINESE GARDENS
}

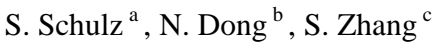 \\ ${ }^{a}$ Buero StadtVerkehr GmbH, Hilden, Germany - sebastian.schulz.q1d@ gmail.com \\ ${ }^{\mathrm{b}}$ College of Architecture and Urban Planning, Tongji University, Shanghai, China - dongnannan@ tongji.edu.cn \\ ${ }^{\mathrm{c}}$ ERA Landscape Planning \& Design Co. Ltd., Shanghai, China - zhangshenghong@erayr.com
}

KEY WORDS: GIS, Data Applications, Green Space Register, Maintenance, Chinese Gardens, Germany, China

\begin{abstract}
:
This paper will set a comparison of current digital database models in China and its successful-proven predecessors in Germany. It will analyse applied tools, structures, targets, and results to identify the potentials and conditions for digital registers specifically aimed at Traditional Chinese Gardens. The challenges of data collection, database maintenance and regular updating, user handling, as well as analysis performance and evaluation will be discussed. A focus will be set on heritage-related attributes as one of the main purposes of the database. By using best-practice examples of German database systems, the paper aims on both identifying the required key attributes for traditional Chinese Garden management and developing a new guideline for digitally-supported heritage preservation and protective maintenance in traditional Chinese Gardens in China.
\end{abstract}

\section{INTRODUCTION}

\subsection{Context}

In the past decades, throughout the hastiness of China's rapid urbanisation, comprehensive urban maintenance and historic preservation has been largely neglected in favour for continuous construction and expansion. Just in recent years, the awareness for heritage preservation has gained importance in urban management. Historic landmarks and ancient heritage sites have been remodelled, rebuilt or revalorized throughout Chinese cities, ancient philosophies and their significance for the built environment have risen to renewed fame.

With the emerging importance of ecological resilience in China, protection and enhancement of recreational green space in urban areas is one of the most important topics in current urban research.

A significant and valuable part of green spaces in China is represented by Traditional Chinese Gardens (TCG). In comparison to the typical urban parks and recreational green, TCG were built for specific purposes or for significant persons and families as a refuge for thinking, creativity or simply relaxation. With their ornamental and extremely vulnerable elements, TCG nowadays are endangered by hordes of visitors, pollution and urban construction. Therefore those gardens demand a special focus on maintenance and protection in today's urban environments.

Supporting the increasing awareness for heritage protection, latest trends of smart city development and digitalisation have opened up new opportunities for data processing in this field.

Digital databases have already helped urban researchers and planners to get to know the manifold urban features, in which green spaces, parks and recreational gardens play a significant role.
In Germany, digital databases with the exclusive focus on green spaces have already been established for many years. They developed from simple inventory lists towards complex management systems, which are being used by city administrations not only to monitor the quality of green spaces, but also to identify cultural and social values as well as to efficiently manage financial control and maintenance efforts on the administrative level.

In China, too, digital green space databases are gaining popularity among administrations and researchers. In comparison to their German counterparts though, many databases are just on the level of digitalised inventory lists.

For Traditional Chinese Gardens, the urban oases of unique design and cultural value, digital applications have not been developed on a larger scale to allow comparison and standardisation. Especially for those types of historic gardens, with their vulnerable and endangered elements and features, a manageable digital platform would be of great benefit for heritage preservation.

It is important to clarify, to which extent digital applications can support maintenance and protection efforts for TCG in China, and what kind of preconditions those applications might underlie.

\subsection{Methodology}

This article will study the specific attributes of traditional Chinese Gardens (TCG) and their requirements towards maintenance and preservation.

Their implementation into digital databases, as a crucial step for comprehensive management, will be analysed for German and Chinese cases. A special focus will be set on the typical attributes of TCG, which differ from ordinary park inventory. 
Based on those attributes and specific findings, the article will depict future perspectives on how TCG preservation and maintenance can be supported by digital databases and applications.

\section{DIGITALISATION OF TRADITIONAL CHINESE GARDENS}

\subsection{Historic Value}

Traditional Chinese Gardens represent a significant part of Chinese history, culture and philosophy (Chen \& Jia, 2015). Their styles and landscape designs have evolved over thousands of years and are still present in today's urban recreational and open space planning in China.

As a reflection of ancient Chinese cosmology, aesthetics and philosophy, the space in TCG provides unparalleled value for historical research and cultural education. The numerous illustrations, horticultures or furniture present a complex of traditional arts, synthetized by philosophical theory and skilful craftsmanship.

With the influence of pictorial art on the capacity to form a small-scale or miniature landscape, TCG also bring endemic enlightenments for today's landscape design (Paolillo, 1995). "By transplanting the notion of experiential space into traditional painting and poetic theories, the Chinese Garden was established as both an historical prototype and a national epitome of modern space" ( $\mathrm{Lu}, 2011)$.

This article uses the definition for Traditional Chinese Gardens, which was defined in the "Chinese Landscape Gardening Theory" (Zhang, 1991). Accordingly, the landscape environment in limited space has a natural imagery and implies spiritual realm, created by approaches of traditional crafts and usually consists of architectures, plants, stones and rocks, water elements, as well as birds and fishes.

Based on this definition, there are three main categories for TCG, which are most widely recognised by Chinese researchers (Zhou, 1990):

$$
\begin{array}{ll}
\text { - } & \text { Royal gardens } \\
\text { - } & \text { Private gardens } \\
\text { - } & \text { Temple gardens }
\end{array}
$$

Royal gardens mainly developed in northern China, with its most famous cases located in the Beijing area. Private gardens typically reflect the aesthetic mentality of philosophers and their scholars, with its most notable examples in the Jiangnan area (Yangtze-River-Delta). Both kinds of gardens were exclusively used by wealthy or royal single persons or families, but nowadays can be visited by the public. Temple gardens are mainly located in China's famous mountain resorts and are commonly designed in a more open and accessible structure. The layouts and designs, as well as the construction age can vastly differ among the three categories and even within one category. Nevertheless, all three categories share common landscape elements and art characteristics, only varying in their emphasized design focus.

\subsection{Landscape Elements and Architecture}

In distinction from common urban parks, TCG feature special elements and architectures. Many elements, uniquely designed and crafted, are not exchangeable or replaceable. In the tradition of ancient philosophy for TCG, the destruction of a single element can already lead to a significant loss of beauty and spiritual function of the garden (Peng, 1986). The combination of elements creates a garden enclosed by walls, which reflects an idealised miniature landscape of the natural environment.

(1) The first typical elements in TCG are artificial rock formations as an integral part of the garden landscape. They are the symbol of virtue, stability and endurance. Rock elements in TCG can be classified in either

- $\quad$ piled-up rock formations, or

- detached single rocks.

The rocks are usually of limestone and were sculpted by erosion. As a sedimentary rock, limestone is rather prone to weathering and therefore easy to change its form, even though the process can take several years until the rock's ultimate shape, which makes it suitable as an element in a carefully designed (spiritual) garden. This concludes that maintenance and preservation efforts are rather high for specifically designed or sculpted limestone rocks in TCG.

(2) As the counterpart of rocks, water is the second major element in TCG. In a philosophical interpretation, water represents the "yin", while rocks represent the "yang" in Chinese philosophy. In other words, the softness of the water contrasts with the solidity of the rocks (Chen \& Gang, 2011).

Water in TCG is most often used in form of ponds or small lakes, which are enriched by flora and fauna.

(3) TCG also feature specific flowers and trees, which are not always common for other parks and gardens. The plants in TCG are not only placed for beautification purposes, but each of them has a unique symbolic meaning and shows the owner's aspirations and interests (Peng, 1986). The following plants are the most common or typical species, which can be found in TCG:

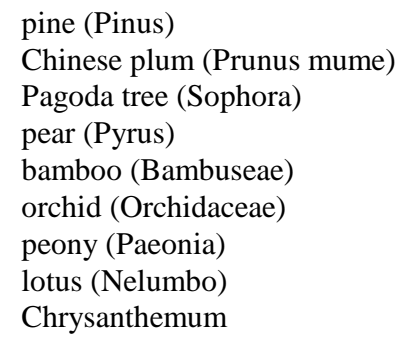

Several of the above listed species need intensive care and maintenance, such as the orchid or peony. TCG flora continuously alters its posture, shape or colour over the year. All plants in the garden have different lifespans, with only trees such as the pine, cypress, or pagoda tree possess longevity. This concludes that maintenance and preservation efforts are rather high for TCG flower beds, which sometimes even host endangered species. While also considering the historical context for many TCG, many ancient trees and long-living plants are also in need for special and intensive maintenance and protection.

(4) Architecture elements play an important role in TCG. Rather than functioning as a main feature, buildings surround or even enclose the garden space. Building structures have high aesthetic requirements on their architectural form and shape, as they are part of the holistic ensemble and should integrate into the natural environment (Peng, 1986). 


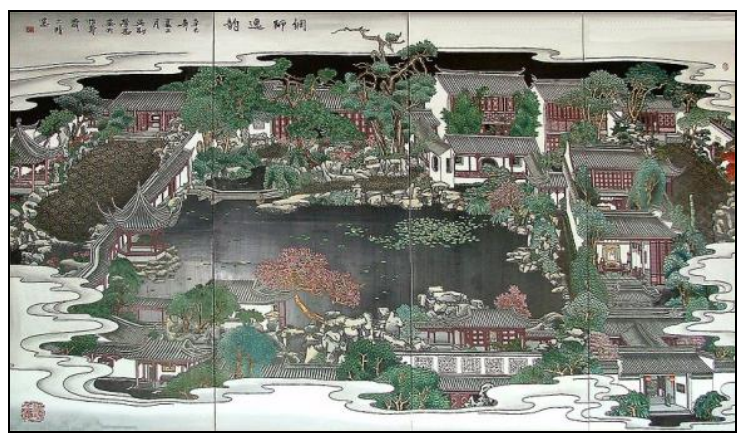

Figure 1. Surrounding architectural features on a painted map of the Master of the Nets Garden, Suzhou (๔ Wikimedia commons)

Several buildings and architectural features are common in TCG: Pavilion (亨)

Windowed veranda (轩)

Floor (楼)

Attic（阁）

Shed (榭)

Platform (台)

Gallery (廊)

Temple (殿)

Hall (堂)

Even the design of building adornments, such as doors, windows or ceilings also integrates with the garden's natural features and even expresses a certain philosophical symbolism.

Important to notice for architecture elements in TCG is their difference from the generally listed architectures and buildings as so called "cultural relicts" by Chinese cultural institutions. As a result, TCG buildings don't earn a special status per se for absolute heritage protection (Yong, 2004).

As their building materials traditionally consist of wood, brick and mud, especially older buildings are easily affected by environmental influences and damages made by daily visitors. Regular maintenance and repair are the most needed measures, however the lack of supply of traditional materials and knowledge of specific craftsmanship make protection efforts difficult (Yong, 2004).

\subsection{Digitalisation of TCG Elements}

In order to survey TCG elements as described in chapter 2.2, several studies were undertaken by researchers to digitally map Traditional Chinese Gardens. First innovative studies with a special focus on heritage preservation surveyed the elements of TCG, based on 3D modelling techniques and photogrammetry systems (Liu et al., 2009; Xue et al., 2011).

Those provided first hand data of sometimes hardly accessible areas in TCG (e.g. underwater objects, rock formations, etc.), which are crucial for maintenance and preservation management (Shen \& Zhang, 2012). The 3D data models have helped to register and map the traditional designs and structures, which give an overview of the current state and condition of a TCG. On the other side though, this does not allow specific maintenance management based on its digital database library, as 3D modelling does not include attribute-specific categorisation of TCG elements and specific needs.

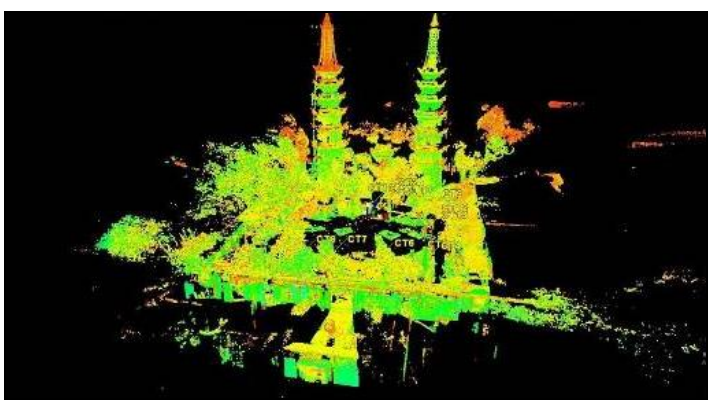

Figure 2. Point cloud data of a TCG

(C) Shen \& Zhang, 2012)

At this point it can be stated that no general efforts have been undertaken for a countrywide or even international classification for the digitalisation of TCG in order to efficiently manage maintenance and to contribute to heritage protection.

Regarding inventory databases, the City of Suzhou in Jiangsu Province possesses the most advanced data collection. For its 9 major Traditional Chinese Gardens, the local administration regularly surveys 44 attributes in 9 categories in a digital offline database. This database consists of data tables so far, with no further functions, such as combinations with GIS maps or other analysis tools (Wang \& Feng, 2008).

\begin{tabular}{|c|c|c|}
\hline Categories & $\begin{array}{c}\text { Attr. } \\
\text { ID }\end{array}$ & Attributes \\
\hline Buildings (A) & $\begin{array}{l}\text { A-1 } \\
\text { A-2 } \\
\text { A-3 } \\
\text { A-4 } \\
\text { A-5 } \\
\text { A-6 } \\
\text { A-7 }\end{array}$ & $\begin{array}{l}\text { board, hall, windowed } \\
\text { veranda, temple } \\
\text { floor, attic } \\
\text { shed, boat house } \\
\text { pavilion } \\
\text { gallery } \\
\text { wall } \\
\text { others }\end{array}$ \\
\hline $\begin{array}{l}\text { Structures } \\
\text { (B) }\end{array}$ & $\begin{array}{l}\text { B-1 } \\
\text { B-2 } \\
\text { B-3 } \\
\text { B-4 } \\
\text { B-5 } \\
\text { B-6 } \\
\text { B-7 } \\
\text { B-8 }\end{array}$ & $\begin{array}{l}\text { artificial hill } \\
\text { stone peak } \\
\text { revetment } \\
\text { raised flower bed } \\
\text { bridge } \\
\text { pavement } \\
\text { Small article facilities } \\
\text { others }\end{array}$ \\
\hline $\begin{array}{l}\text { Furnishings } \\
\text { (C) }\end{array}$ & $\begin{array}{l}\text { C-1 } \\
\text { C-2 } \\
\text { C-3 } \\
\text { C-4 } \\
\\
\text { C-5 } \\
\\
\text { C-6 } \\
\text { C-7 } \\
\text { C-8 } \\
\text { C-9 }\end{array}$ & $\begin{array}{l}\text { bench, chair } \\
\text { teapoy, table, stage, desk } \\
\text { Kang, bed } \\
\text { pendant(palace lantern, } \\
\text { horizontal inscribed board, } \\
\text { couplet, hanging panel ) } \\
\text { decorations(rocks, porcelain, } \\
\text { bronze ware, desk panel, } \\
\text { clock) } \\
\text { calligraphy and painting } \\
\text { inscriptions on precipices } \\
\text { book stone, inscription } \\
\text { others }\end{array}$ \\
\hline Plant (D) & $\begin{array}{l}\text { D-1 } \\
\text { D-2 } \\
\text { D-3 } \\
\text { D-4 }\end{array}$ & $\begin{array}{l}\text { old and famous plants } \\
\text { Ornamental Plants } \\
\text { bonsai } \\
\text { others }\end{array}$ \\
\hline
\end{tabular}




\begin{tabular}{|c|c|c|}
\hline Categories & $\begin{array}{l}\text { Attr. } \\
\text { ID }\end{array}$ & Attributes \\
\hline $\begin{array}{l}\text { Environment } \\
\text { (E) }\end{array}$ & $\begin{array}{l}\text { E-1 } \\
\text { E-2 } \\
\text { E-3 } \\
\text { E-4 } \\
\text { E-5 }\end{array}$ & $\begin{array}{l}\text { atmosphere } \\
\text { weather } \\
\text { water quality } \\
\text { soil } \\
\text { others (acid rain, noise etc.) }\end{array}$ \\
\hline $\begin{array}{l}\text { Development } \\
\text { control area } \\
\text { (F) }\end{array}$ & $\begin{array}{l}\text { F-1 } \\
\text { F-2 } \\
\text { F-3 } \\
\text { F-4 }\end{array}$ & $\begin{array}{l}\text { buildings at control area } \\
\text { municipal infrastructure } \\
\text { environmental pollution } \\
\text { source } \\
\text { others }\end{array}$ \\
\hline $\begin{array}{l}\text { Visitor flow } \\
\text { volume (G) }\end{array}$ & - & 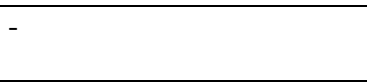 \\
\hline $\begin{array}{l}\text { Security } \\
\text { management } \\
(\mathrm{H})\end{array}$ & $\begin{array}{l}\mathrm{H}-1 \\
\mathrm{H}-2 \\
\mathrm{H}-3\end{array}$ & $\begin{array}{l}\text { Security inspection situation } \\
\text { accident cases } \\
\text { large exhibition fete activity }\end{array}$ \\
\hline $\begin{array}{l}\text { Infrastructure } \\
\text { (I) }\end{array}$ & $\begin{array}{l}\mathrm{I}-1 \\
\mathrm{I}-2 \\
\mathrm{I}-3 \\
\mathrm{I}-4\end{array}$ & $\begin{array}{l}\text { electric appliance and power } \\
\text { distribution room } \\
\text { fire-fighting equipment } \\
\text { protection scope of electric } \\
\text { protection scope of water } \\
\text { supply and drainage }\end{array}$ \\
\hline
\end{tabular}

Table 3. Suzhou TCG database categories and attributes (SMG, 2012)

\subsection{Maintenance and Protection Efforts}

The maintenance and protection efforts vary between gardens and most of all city administrations. Less is known about many TCG in China, as information sources are not openly accessible in many cases.

As described in the previous chapter, the city of Suzhou has the most advanced database, which can be investigated. Since Suzhou's gardens were listed as a UNESCO World Heritage Site in 1997, local administrations enacted several rules, such as a relics protection scheme, tourism control rule, old and famous trees protection rule or ancient architecture maintenance guidelines in addition to their developed TCG database.

Local administrations evaluated the TCG heritage sites after a revision of the "Suzhou Garden and Landscape System Management Regulation", which aims on optimising protection and preservation efforts as support of the World Heritage listing. Digital tools were not part of the initial phase in the late 1990's, although research databases at universities and research institutions existed. It is expected that digital databases will be applied in the near future for daily monitoring and information feedback, but further specifications are unknown at this point. For now, a scientific evaluation on maintenance and protection efforts cannot be performed by digital databases. Nevertheless, the new evaluating system could improve more comprehensive scientific approaches.

In addition, the Suzhou Protection and Supervision Center (SPSC) has been founded as a management institution, which supervises the World Heritage gardens. It set a guideline catalogue for the database categories regarding database update intervals and quality monitoring (Feng, 2011).

\begin{tabular}{|c|c|c|}
\hline \multicolumn{2}{|c|}{ Categories } & $\begin{array}{c}\text { Database monitoring } \\
\text { period }\end{array}$ \\
\hline \multicolumn{2}{|l|}{ Buildings (A) } & Once every 2 years \\
\hline \multicolumn{2}{|l|}{ Structures (B) } & Once every 2 years \\
\hline \multicolumn{2}{|c|}{ Furnishings (C) } & Once every 2 years \\
\hline \multicolumn{2}{|l|}{ Plant (D) } & monthly \\
\hline \multirow{4}{*}{$\begin{array}{l}\text { Environment } \\
\text { (E) }\end{array}$} & $\begin{array}{l}\text { air } \\
\text { quality }\end{array}$ & daily \\
\hline & weather & daily \\
\hline & water & monthly \\
\hline & soil & annually \\
\hline \multicolumn{2}{|c|}{$\begin{array}{l}\text { Development control area } \\
\text { (F) }\end{array}$} & Once every 2 years \\
\hline \multicolumn{2}{|c|}{$\begin{array}{l}\text { Passenger flow volume } \\
\text { (G) }\end{array}$} & daily \\
\hline \multicolumn{2}{|c|}{ Security management $(\mathrm{H})$} & Once every 3 months \\
\hline \multicolumn{2}{|c|}{ Infrastructure (I) } & Once every 2 years \\
\hline
\end{tabular}

Table 4. Maintenance Intervals for Suzhou's TCG (Feng, 2011)

Information is usually gathered by the SPSC on site. Unfortunately, less is known about attribute condition categories, how they are surveyed or recorded and what consequences result for maintenance and protection efforts out of the collected data.

Besides of physical protection and maintenance, the Suzhou landscape administration was committed to promote people's cognition and awareness of TCG protection by organising seminars, exhibitions and voluntary activities to spread knowledge among citizens, especially in schools, universities and local communities.

It remains unsolved at this point, whether the efforts have improved the current situation or if any effects on the preservation can be measured. As it can be observed for now, many concepts, technologies and digital data exist, but are often not implemented properly into a holistic database system or register, which can be used for advanced green space or TCG management.

\section{DIGITAL GREEN SPACE DATABASES}

\subsection{Purpose}

Green Space Databases or Registers can be widely used for monitoring conditions and developments of green structures, gardens and parks. With increasing opportunities of digital data, several city administrations worldwide developed advanced management systems to not only monitor, but to control green space-specific demands and requirements.

In Germany, first ideas of digital databases date back to the late 1980 's, when topics of sustainable development as well as financial shortcomings of city administrations led to an increased significance of advanced urban management (GALK, 2000). Maintenance costs for public green spaces are permanently increasing over the years and already more than 
doubled since the year 2000 (Eschenbruch, 2012). In order to maintain and manage urban green spaces within a cost-efficient framework, digital databases, so called "Green Space Information Systems" (GRIS) supported administrative decision-making by calculating needs, demands, cost structures, workloads and/or staff management. It was the purpose to not only gain a broad overview of the Status Quo, but to digitally manage future (sustainable) development for public, urban green spaces (GALK, 2000).

Over the years, specific guidelines for GRIS databases were developed and continuously updated by a specialised workgroup of the Garden Department Management Conference ("Deutsche Gartenamtsleiterkonferenz" (GALK)) (GALK, 2000).

\subsection{Structure \& Database Management}

The GRIS guidelines set several recommendations for structures and database architectures. Common to all databases investigated is the general technology based on GIS services in combination with SQL database tables, controlled and updated with specially designed user interfaces (SenStadtUm Berlin, 2015; Reinheckel, 2007; Schneider, 2007).

Research among GRIS databases of several German cities has shown that structures and technologies differ to a vast extend. The structure and methodology is often linked to the specific requirements for each city, also representing the various organisational schemes of city departments in charge for green space management. Not at least, funding and financial budgets for software and database servers have a significant impact on structural and technological depth of GRIS systems.

In case of the GRIS of Berlin, one of the most advanced systems in Germany, database management, data input and data analysis are in responsibility of different administrational levels. The System consists of several tools and applications, such as a data input interface, which is accessible for all local administrations for regular updates and statistical analysis. Latest system updates also allow data collection via mobile devices. Further applications include a GIS-application for visualisation, a photo register, and a database application for maintenance calculation (SenStadtUm Berlin, 2015).

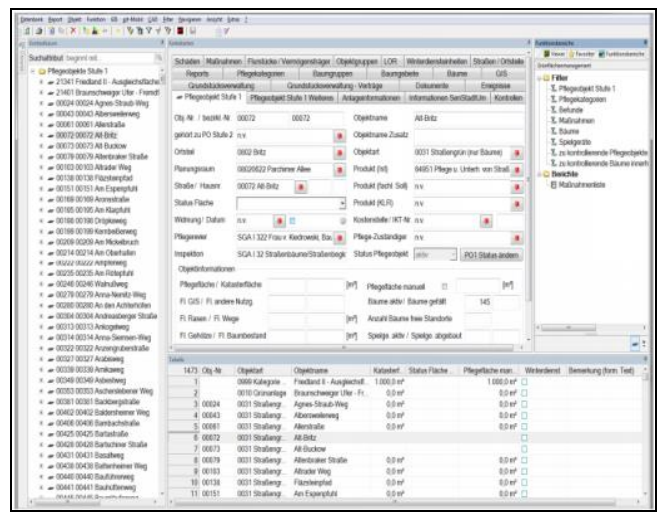

Figure 5. Database Interface of GRIS Berlin (C) SenStadtUm Berlin, 2015)

\subsection{Attributes and Context}

Attributes mapped and depicted in GRIS systems are organised by object catalogues. The object catalogues are in most cases developed by city administrations. However, in most cases, they follow the object catalogue developed by the GALK in 1995, which aims on creating a standardised file of categories, subcategories and attributes for German GRIS (SenStadt IC 215, 2010).

The GALK-catalogue distinguishes 13 basic categories of public green and open spaces, in which parks and gardens just represent one of those categories. Others include sports grounds, playgrounds, forests, biotope-areas, or cemeteries. Sub-categories, listed by the GALK in its so called area content database ("Flächeninhaltsdatei"), specify the exact elements and attributes collected for a GRIS (GALK 1995; Eschenbruch, 2015).

The area content database defines 6 main categories with fixed key IDs for digital green space databases. For each main category, there are several sub-categories organised, in which all single attributes being listed.

\begin{tabular}{|c|l|c|c|}
\hline Key ID & Main Category & $\begin{array}{c}\text { No. of } \\
\text { Sub- } \\
\text { categories }\end{array}$ & $\begin{array}{c}\text { No. of } \\
\text { Attributes }\end{array}$ \\
\hline 1.000 & Vegetation & 7 & 23 \\
\hline 2.000 & Paved areas & 2 & 13 \\
\hline 3.000 & Water bodies & 2 & 4 \\
\hline 4.000 & $\begin{array}{l}\text { Constructed } \\
\text { elements }\end{array}$ & 6 & 15 \\
\hline 5.000 & Furnishing & 5 & 13 \\
\hline 6.000 & Buildings & 5 & 6 \\
\hline
\end{tabular}

Table 6. Categories of GALK area content database (GALK, 1995)

Because of the manifold elements and plant species of public green spaces, the biggest challenge for GRIS object catalogues is to create a manageable scope of attributes and contexts.

The guideline object catalogue by GALK consists of 74 summarized attributes, which can be specified further for plant families, species, etc. (GALK, 1995; SenStadt IC 215, 2010). Therefore special attributes, such as for TCG, are not commonly surveyed or standardized by general object catalogues.

\subsection{Maintenance and Protection Management}

A crucial part of many green space systems is an application for maintenance management. This presupposes that each surveyed attribute is linked with object-specific operating data ("Betriebsdaten"). For the Berlin GRIS, an operating data management tool sets maintenance standards for each attribute, such as average time and financial expenditures or costs of external maintenance (e.g. private contractors) (Reinheckel, 2007).

The GALK published a list with average costs for most relevant attributes for its area content database (Eschenbruch, 2015). The list gives an overview of park and garden elements and their average cost per unit (either price/sqm or price/piece). 


\begin{tabular}{|c|l|c|}
\hline $\begin{array}{c}\text { Key } \\
\text { ID }\end{array}$ & \multicolumn{1}{|c|}{ Attribute } & $\begin{array}{c}\text { Unit Cost in } \\
\boldsymbol{\epsilon} / \text { year }\end{array}$ \\
\hline 1110 & Grass-Lawn & 0.65 \\
\hline 1120 & Sports-Lawn & 2.50 \\
\hline 1130 & Meadow & 0.39 \\
\hline 1211 & Tree (Road) & 58.50 \\
\hline 1270 & Tree (Green Space) & 52.00 \\
\hline 1320 & Ornamental Bush & 3.90 \\
\hline 1340 & Hedge & 10.00 \\
\hline 1410 & Seasonal Planting/Flowers & 65.00 \\
\hline 2110 & Water-bound Cover & 1.79 \\
\hline 2120 & Pavements & 1.30 \\
\hline 2130 & Tile Surfaces & 1.30 \\
\hline 2160 & Sand Surfaces & 13.00 \\
\hline 2190 & Stairs & 1.30 \\
\hline 3110 & Ponds / Lakes / Biotopes & 1.30 \\
\hline 3150 & Bank border & 3.90 \\
\hline 3220 & Moat & 1.70 \\
\hline 4100 & Walls / Concrete Elements & 1.30 \\
\hline 4200 & Bridges & 65.00 \\
\hline 4410 & Fences (1,00m height) & 1.30 \\
\hline 4419 & Gates (1,00m height) & 26.00 \\
\hline 5310 & Bench & 52.00 \\
\hline 5320 & Tables & 65.00 \\
\hline 5330 & Trash Bins & 19.50 \\
\hline
\end{tabular}

Table 7. Selected Attributes for Maintenance Costs (Eschenbruch, 2012)

In addition, average financial efforts for maintenance are defined by GALK guidelines for each type of green space. Further analysis of a TCG in Germany, namely the Qian Garden in Bochum (RUB, 2015), made it possible to estimate annual maintenance costs in comparison to the GALK estimates for usual parks and other types of urban green space. It has to be explained that Qian Garden is one of the most original types of TCG private garden outside of China, even though it is not a truly historical structure, but was built in 1990 .

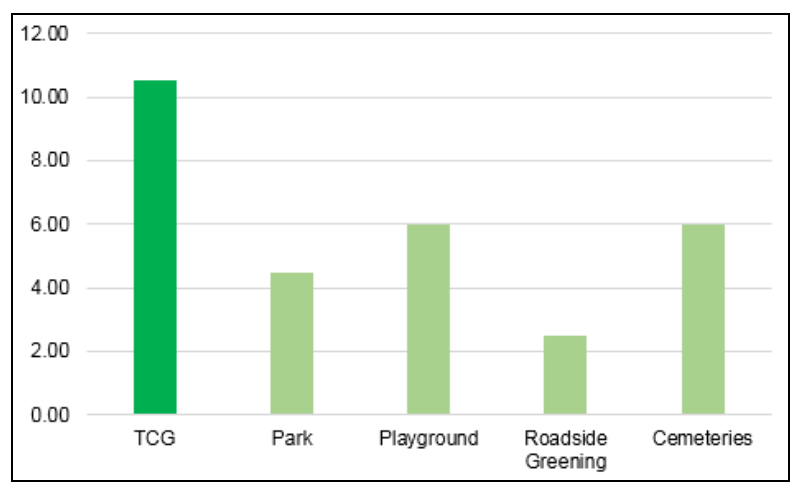

Figure 8. Average Annual Costs in $€$ per sqm
The simplified calculation of average costs shows significant differences in maintenance efforts related to each type of green space, especially in comparison to TCG. Therefore the design of a park, its size, use and location matter for concise estimations of maintenance efforts. It has to be noted that those numbers depicted above, do not take historically valuable objects or heritage-protected attributes into account, due to a lack of data resources in combination with GRIS-maintenance management. It can be expected that unit costs are largely higher for specially treated historical objects, such as the ones be found in Traditional Chinese Gardens in China.

Another weak spot in the GRIS-based maintenance revolves around data accessibility and information sharing. As stated for several GRIS systems in Germany, only government administrations have access to the databases for maintenance management. Parks or green areas in private hand, even though they might be used by the public, are not implemented and therefore are excluded from any kind of analysis or calculation. This highly affects the few Chinese Gardens or oriental style gardens in Germany, which are often run and maintained by private initiatives or companies. It is possible that there exist databases in private hand, which were not accessible for this study. For further and more concise research, it is necessary to compare larger datasets and calculation numbers.

\section{DEVELOPING DIGITAL APPLICATIONS FOR TRADITIONAL CHINESE GARDENS}

\subsection{Databases for TCG}

As seen in chapter 2, first database structures have been developed for TCG in China. Nevertheless, a holistic approach has not been undertaken, leaving the positive best-practice examples, e.g. the case of Suzhou, stand-alone features. In fact, also the Suzhou case showed that digital applications in the meaning of commonly usable management systems for a sustainable development and protection of TCG cannot be observed at this point.

The German developments of GRIS systems in chapter 3 showed that those systems exist, although not specifically for TCG purposes. Several attributes and categories of German GRIS are not compatible with the special demands and requirements for the partly sensitive TCG elements, especially for its heritage features. Nevertheless, the generally standardised catalogue with its estimated average costs represents a manageable guideline for the development of a digital database and maintenance application.

Regarding TCG, developing such guidelines and databases can equitably manage costs structures and workload on preservation of valuable, but often improperly maintained TCG.

First steps have been taken towards the development of unified and standardised database guidelines. In a first step, several TCG structures in the Yangtze-River-Delta have been surveyed as test objects and mapped digitally with CAD and GIS. The GIS layers consist of general information about the mapped attributes according to the Suzhou database example and function as base layers within the GIS system. The data tables are compatible with SQL queries, thus can be further processed over user input interfaces, which have yet to be developed. 


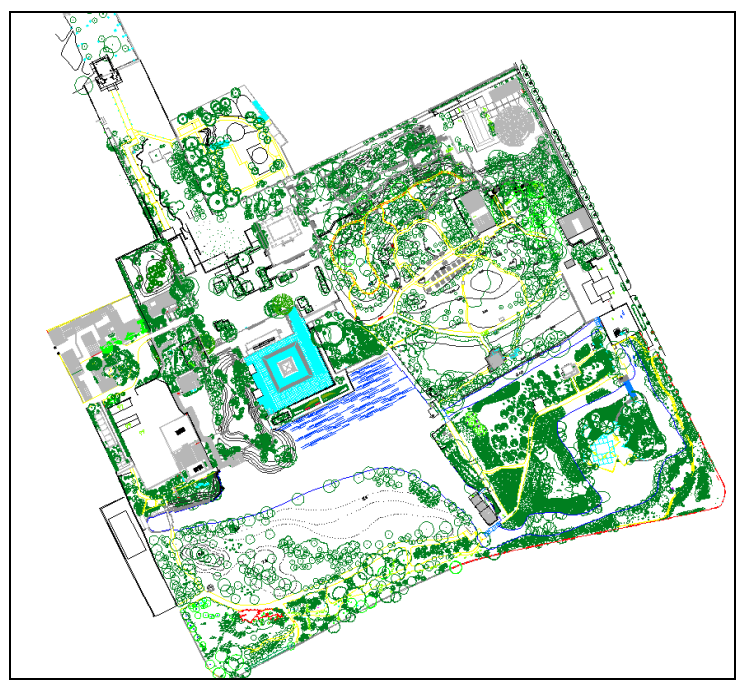

Figure 9. Mapped TCG Database Attributes

At this time, the digital database for TCG is no more than an advanced inventory list, which still lacks usage for maintenance management. It is just a small step further than previous attempts, which have been mentioned in the beginning of this article. Nevertheless, the visualisation and data interaction is already a major step for current administrative information support.

\subsection{Maintenance Management and Protective Measures}

What still needs to be evaluated at this point is the integration of maintenance intervals and its management for TCG. Surveys and informal talks with TCG management administrators have brought to light that current maintenance is largely managed by paper lists, filled out by service staff (with some exceptions).

For the next steps of the TCG database application, pilot projects will be developed in the coming months for the test of digital maintenance protocol recordings via mobile devices and smartphone apps, which will be an integral part of the database system. Real time data transfer from the maintenance staff on site to the database will rapidly accelerate the information flow between administrations (provision of financial and personnel resources) and local TCG maintenance supervision. In addition, central administrations gain an overview of multiple TCG within the area, allowing comparison and analysis based on reported information.

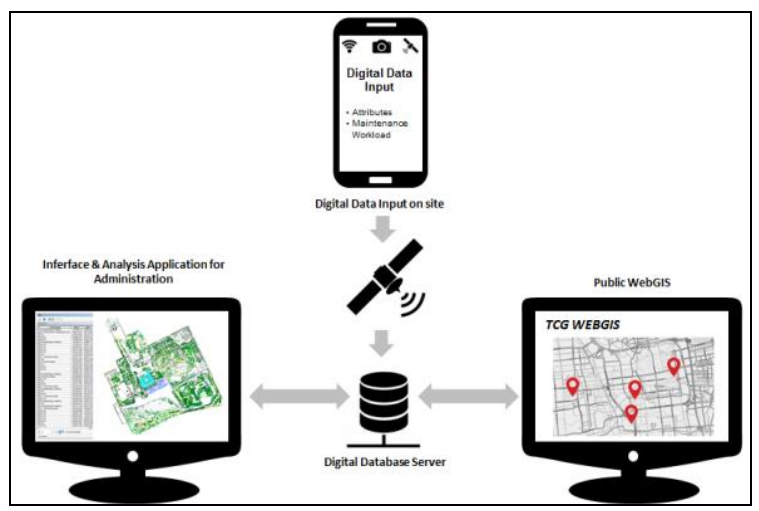

Figure 10. Model of information flow
This gives different management levels the opportunity to not only share information, but to also react properly and in advance towards changing circumstances with the ability to enact protective measures on time.

\subsection{Outlook}

The standardised database model with its additional applications for maintenance, as described in previous subchapters, can be seen as the basic first step in developing such a system on a larger scale.

For future purposes, several extensions and additions are possible. The internal use for local administrations can just be one part in this matter. As the case study of Suzhou has shown, public awareness and ongoing education on heritage protection as well as respectful treatment of historic structures plays a significant part. Here, the database can contribute through further applications accessible for public, e.g. in form of WebGIS applications or even mobile apps, which use data feeds from the database system.

Examples of such WebGIS systems can already be seen for several purposes, such as the Shanghai Urban Forestation Foundation GIS.

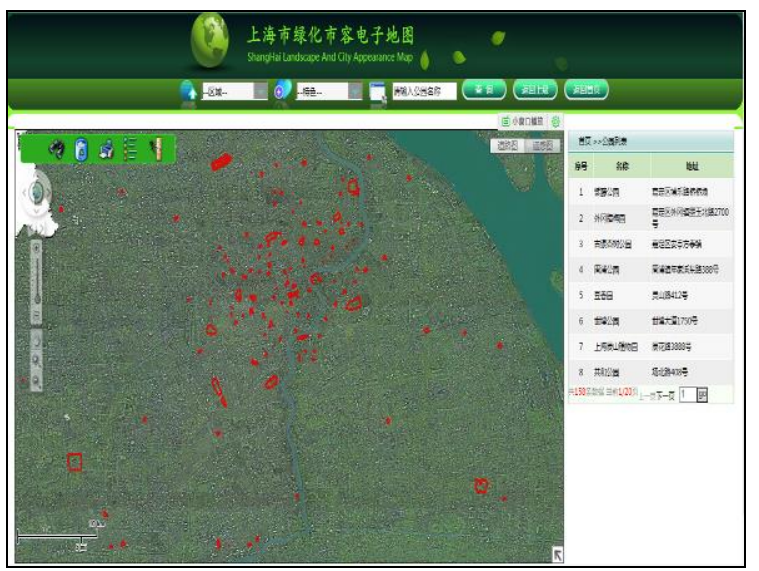

Figure 11: Shanghai Urban Forestation Foundation GIS (C) SUFF, 2015)

By enabling the public to interactively participate in the information sharing process, the TCG database system can guarantee sustainability and longevity for Traditional Chinese Gardens in China.

\section{CONCLUSION}

Protecting and preserving Traditional Chinese Gardens remains a difficult task within the fast-paced urban development in China. Environmental effects and thousands of visitors every day harm its sensitive structures and objects. There is no doubt that for sustainable protective measures, standardised guidelines need to be developed. The current state of individual maintenance efforts and consequently, extremely varying conditions of historic TCG structures across the country cannot be continued with the intentions of long-lasting preservation.

The digital database with its applications holds the potential of creating a comprehensive information platform, which could connect stakeholders, managers, experts and the public. With 
the use of standardised data and comparable analyses, a new level for TCG protection can be reached.

What needs to be mentioned at last is that further research is needed for a deeper understanding of maintenance and protection efforts for TCG. The current administrational responsibilities in the terms of maintenance and protection should be further analysed, for example whether restructured competences are required by a digital database management system. In a future step, the database schemes can be integrated into comprehensive digital applications and should take standardised formats or attributes, which can also be applied on the international level.

\section{REFERENCES}

Chen, G., 2011. Landscape architecture: Planting design illustrated (3rd Ed.). ArchiteG, Inc., p. 145.

Chen, S.; Jia, L., 2015. Current Situation and Protection Means of Traditional Chinese Garden. Journal of Landscape Research, 2015, 7(2): pp. 3-5.

Eschenbruch, H., 2012. Code Numbers for the Construction and Maintenance of Green Spaces. Paper of the GALK e.V., AK "Organisation und Betriebswirtschaft", http://www.galk.de/ arbeitskreise/ak_orga_betriebswirt/down/kennzahlen_eschenbru ch_120529.pdf (29 May 2012).

Feng, M., 2011. Enactment of the "World Heritage Classical Garden of Suzhou Monitoring Rule". Suzhou Daily, http://www.dwrh.net/a/wenhua/shiyi/20110427/34858.html (27 April 2011).

Fung, F., 2007. Chinese classical garden research literature analysis. Tianjin University Press, Tianjin.

GALK (Ed.) AK "Organisation und Betriebswirtschaft”, 1995. Paper on „Suggestions for a Green Space Database“ (Orig. „Empfehlung für eine Grünflächen-datei“). http://www.galk.de/gris/down/galksys.pdf (16. Sept.1995)

GALK (Ed.) AK “Organisation und Betriebswirtschaft”, 2000. Guideline for the creation and updating of Green Space Information Systems (GRIS).

http://www.galk.de/gris/down/leit1.pdf (5. April 2000)

Liu, Q. et al., 2009. Multiple Baseline Digital Close Range Photogrammetric System in the Application of Classical Garden Buildings. Three-Dimensional Reconstruction. Journal of Northwest Forestry College, 2009 Ed., pp. 224-227.

Lu, A., 2011. Land of idyllic beauty: Wen zhengming 1533 "the humble administrator's garden atlas" space research [J]. Architectural culture research, 2011, 00:269-324.

Paolillo, M., 1995, Forging the Garden - The Yuanye and the Significance of the Chinese Garden in the 17th Century. East and West 53, 1-4 (December 2003), 209-239.

Peng, Y., 1986. Chinese Classical Gardens Analysis. China Building Industry Press, Beijing.

Reinheckel, U., 2007. Effective Fulfillment of Tasks with GRIS. Experiences of the Green Space Administration Berlin.

Stadt+Grün, 56 (1), pp.22-28.
Ruhr-University Bochum (RUB) (Ed.), 2015. The Chinese Garden e.V. Society for the Chinese Garden (incl. subpages), http://www.ruhr-uni-bochum.de/cgev/index.html (12. July 2015).

Schneider, K., 2007. Green Space Cadastre and Organisation and Maintenance.Realisation and Standard software.

Experience and Practice of the Green Space Administration Fürth. Stadt+Grün, 56 (1), pp.29-34.

SenStadt IC 215 (Ed.), 2010. Paper on „GRIS in Berlin. Modules „GAIA“ and „GBKat“. Structure Description of Berlin's Green Space Database”. http://www.stadtentwicklung. berlin.de/umwelt/stadtgruen/gris/downloads/galk_systematik. pdf (19 Nov. 2010).

SenStadtUm Berlin (Ed.), 2015. Report "Green Space Information System Berlin. Overview GRIS-Components", Berlin, Germany http://www.stadtentwicklung. berlin.de/umwelt/stadtgruen/gris/downloads/module_gris_berlin _neu.pdf (14 Jan. 2015).

Shanghai Urban Forestation Foundation (SUFF) (Ed.), 2015. Shanghai Landscape and City Appearance Map. (WebGIS) http://218.242.71.44/lhjgis/IndexPark.aspx (14.07.2015).

Shen, C.; Zhang, X., 2012. Presentation for "Three-dimensional Digital Measurement Technology Research and Practice of Traditional Chinese Parks.

http://wenku.baidu.com/link?url=PkoBmu_ER2GEE8qcJ6Nzq UN_yupFpMZTEr0pCD7xu39rmsnrxxQVMy9bHAjYCZquRt Ch4fYbOuaVwN68csIaNZj3IvoGgr8Vo8qSR7fFqEy

Suzhou Municipal Government (SMG) (Ed.), 2012. Surveillance Management Rules for the World Cultural Heritage of Suzhou Classical Gardens. (weblink). http://www.zfxxgk.suzhou.gov.cn/sjjg/szsylhlhglj/szssjwhycgdy lbhjgzx/szssjycje/jcgf/201212/t20121203_179479.html (14.07.2015).

Wang, C.; Feng, J., 2008. Suzhou features of World Cultural Heritage Protection - Retrospect and Prospect for ten years of Suzhou Classical Gardens Protection. Suzhou Daily, A, pp.14, http://www.suzhouculture.cn/showContent.aspx?id=25440

Xue, C. et al., 2011. Garden 3D Digital Mapping. Journal of Research and Application of Modern Surveying and Mapping, 2011 (05), pp. 53-55.

Yan, H., 2013. Research on Regeneration Design of Chinese Traditional Landscape Resources. Tongji University Press, Shanghai.

Yong, Z., 2004. Report at the $15^{\text {th }}$ Meeting of the Chinese Architecture Committee's Academic Seminar of the Cultural Relic Institute "Maintenance and Repair of Traditional Construction and Classical Gardens", Beijing (May 2004).

Zhang, J., 1991. Chinese Gardening Theory. Shanxi People's Publishing House, Taiyuan.

Zhou, W., 1990. History of Chinese classical garden. Tsinghua University Press, Beijing. 